\title{
An Overview of Research on "People-Fire Interactions"
}

\author{
SABURO HORIUCHI \\ Kyoto University \\ Kyoto, Japan
}

ABSTRACT

In this paper, the author describes the recent trend of researches on how people move against a fire, especially those on human behavior for evacuation, classifying them by theme, method, and countermeasures. Many recent researches have applied a simulation model in parallel with increasingly sophisticated contents; however, the author stresses the importance of not posing the eventual goal of each research by misapplication. Further, with the recent increase in studies by researchers such as psychologists, a trend which is much appreciated, the author expects researches in this field will be promoted further through closer commcations.

\section{INTRODUCTION - Necessity and Importance of This Research}

It is assumed that the relation between people and fire started its history as early as the appearance of human beings. This paper overviews the present situation of research on the correlation between the violence to people caused by fire and people's protecting efforts against fire to minimize damage, focusing on the recent trend of research on evacuation, directions of future research development and on expectations.

To clarify the necessity and importance of countermeasures to minimize damage, especially casualties, caused by fire, a simple flow chart is presented to identify the role and characteristics of various measures in the whole fire-protection scheme, as shown in figure 1 below.

If any one of countermeasure-chains shown in Figure I is always available to work completely, safety can be maintained, or restored with least damage even when a fire breaks out. However, since any one measure cannot be $100 \%$ reliable in reality, generally, a few of them must be combined to achieve the intended goal. For the purpose of fire protection for buildings as well as minimizing casualties and property damage caused by fire, a most effective (i.e., highly reliable and economic) plan is eventualiy required.

Table 1 presents two major groups of countermeasures, classified into the "physical countermeasures" using equipment and apparatus for fire protection, and the "human countermeasures" emphasizing personal attention and behavior. 
Fig. 1. Flow Chart of Countermeasures against Fire

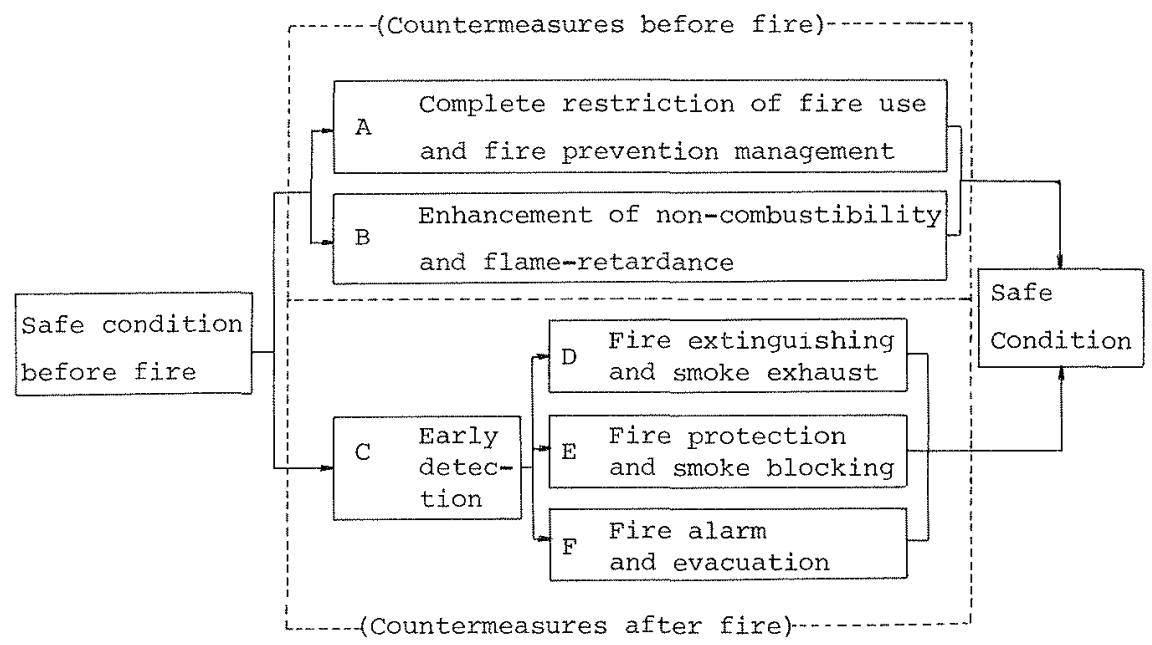

As shown in Figure 1 and Table 1 above, the field of physical countermeasures has been upgraded through automatization by taking advantage of recent technical innovation. On the other hand, there still exists another field requiring human involvement, which cannot be substituted by physical means, as described in $A$ and $F$ of Figure 1 and (a) and ( $f$ ) of Table 1. (However, the starred "Actions by firemen" will be taken into account separately.)

In future, more emphasis should be put on research into "human countermeasures" among others, especially on solution of problems concerning with human psychology and behavior in case of emergency.

\section{RECENT TREND OF RESEARCHES}

Research on evacuation, which is the most important part of the study of human behavior in fire, was initiated by Dr. Kikuji. Togawa about 1955 in Japan through his study "On Evacuation Facilities through Observation of Crowd Flow"(1). In 1970 and later, the method using a computer simulation has been widely used for developing various behavior models in Japan, U.S.A. and other countries. An overview on the recent trend of these researches is as follows.

\section{Classification by Theme}

Research focusing on behavior or time to cope with fire. This is a study to be used in making plans such that an evacuation should be finished by the time the hazard occurs, prepared by summarizing human behaviors in a fire and specifying the time requjred to complete each stage.

Recent researches have focused on "the time required for evacuation" and "the time to start evacuation", as well as on the basic and average walking speed. For example, a study (2) to specify the required time and 
Table 1. Classification of Physical and Human Countermeasures corresponding to various Fire stages

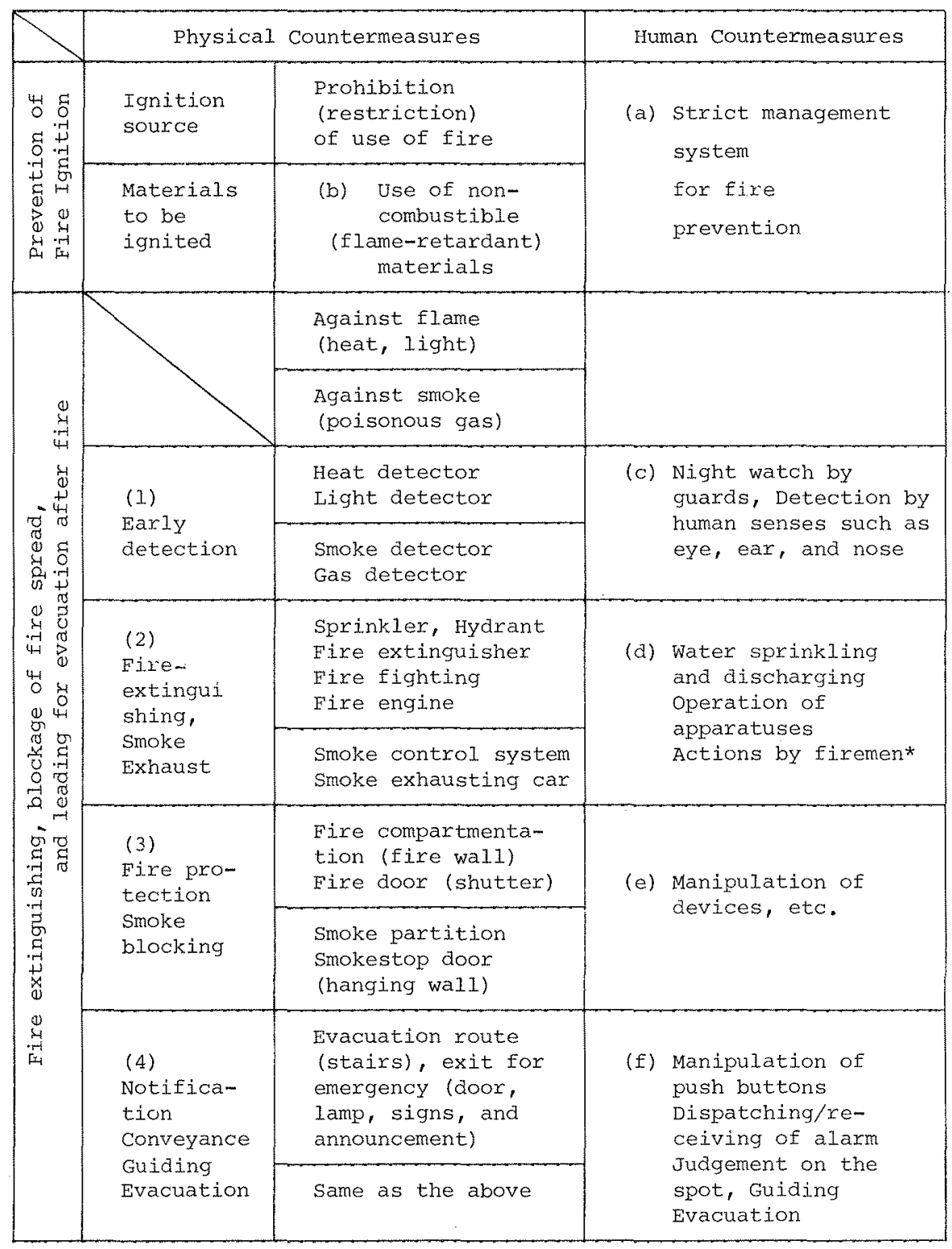

the starting time for evacuation through behavioral experiments and simulations, as well as a study by $T$. Kato(3), was made to study the time to reach the site of the fire after noticing a fire alarm, begining fire fighting and reporting to a fire station by phone, or giving evacu- 
ation directions to the occupants.

Further, a study(4) is made using statistical data of fires on the time elapsed from the outbreak to detection, the time elapsed until a fire station acknowledges, and the time to start evacuation.

Research focusing on human physiology, psychology and human capability.

(1) Capability of the mentally and physically handicapped people and a study of the means of evacuation from their accomodation. A study (5) was made of the time required for relocating patients in hospital by stretcher and wheelchair through experiments, as well as a study ${ }^{(6)}$ with regard to the time elapsed until the mentally retarded awaken from sleep at night in a mental home through observation of fire drills.

There exists another study(7) entitled "The Evacuation of NonAmbulatory Patients from Hospital and Nursing Home Fires: A Framework for a Model" by J. Archea, as well as a study on "Moving Ability of Hospitalized Patients in case of Evacuation"(8) by $K$. Shida, et al.

(2) Study of quantification of behaving ability under psychological or physiological stress. A series of studies have been made by Dr. Jin and others of the Fire Research Institute in an attempt to evaluate peoples ability to select routes for evacuation in smoke. One of these studies is being presented in this symposium(9).

Further, there exist a similar study by A. Hokugo (10), an experimental study of using a maze by $Y$. Watanabe $(11,12,13)$, and a study of the effect of carbon monoxide by $M$. Yung $(14,15)$, et al.

Research on education for fire protection (philosophy and know I edge). Researches have been made recently on what kind of educational training is effective to improve and spread consciousness for fire protection. Doctors $C$. Hayashi and $k$. Mizuno of the Mathematical statistic Research Center of the Ministry of Education started to make studies of this field several years ago, and some of their results have been published $(16,17)$.

\section{Classification by Method}

By case analysis. As of individual fires causing large casulaties or property loss as well as fires which are regarded as valuable data due to their specific cause or damage, 19 have been reported (4I reports alltogether) since 1956 in Japan, these 19 cases include fires in hospitals, high-rise condominiums, theaters, social welfare facilities, cabarets, etc. including 5 department stores (16) and 5 hotels (9) rem ports. Besides them, a few more reports are made on results of investigation and statistical analysis of past cases.

Examples include "Evacuative Behavior in case of The Osaka Science and Technology Center Fire"(18) by S. Horiuchi, Y. Murosaki, A. Hokugo, et al, "The MGM Grand Hotel Fire: a Case study of Human Reaction to Fire"(19) by Dr. Bryan, Report on Investigation Results of 112 unusual Fire Cases $(20)$ by Tokyo Fire Department, "A Study on Behavior Patterns in Fire in Relation to the Type of Building"(21) by $A$. Hokugo, and so on. 


\section{By simulation.}

(1) Link with smoke movement. Studies have been made evaluating safe escape by Iinking an evacuation simulation with forecasts on the dropping of smoke layers in a relatively spacious room, or for making smoke movement forecasts or smoke control plans by linking a smoke movement simulation with the position of an opened door and the time required as obtained from an evacuation simulation.

Examples include "BFTRES II: A Behavior based Computer simulation of Emergency Egress during Fires"(22) by F. Stahl, "Computer Simulation for Total Fire-Safety Design of the New Japanese SuMo Wrestling Headquarters and stadium"(23) by H. Sato. et al, "Design Method of Smoke Control and Evacuation"(4) as one of comprehensive projects by the Ministry of Construction, and so on.

(2) Simulation for supporting behaviors. Studies have been made, incorporating into evacuation simulations the behavior of those who are engaged in leading, supporting, transferring by stretcher, rescue, etc. during evacuation, so as to determine priorities of people to be rescued in accommodation for the handicapped or for determining the manpower necessary for leading them to safety.

Examples include "Escape and Rescue Model"(24) by D* M. Alvoid, "A Study on Evacuation Simulation for Supporting Behaviors"(25) by Y. Murosaki, et al, and "An Evacuation Method of Life Risk in case of Building Fires"(26) by K. Shida, et al.

(3) Simulation as a game. Development and researches for training simulators during evacuation are currently being made.

Examples include "Future Directions for Research and Development" (27) by J. Sime, "Attack to the Simulation Game for Hotel Fires"(28) by K. Kobayashi, and "An Attempt of Evacuation Practice as a Game" (29) by K. Iwaki.

\section{By experiments.}

(1) Identifying the flow coefficient and confluence ratio by experiments.

Attempts have been continuously made through a series of expeximents to clarify the flow coefficient (flow rate) and confluence ratio in a corridor and staircase, which is regarded as a premise for calculation of evacuation.

Examples include "Experimental Study on Escape Direction"(30) and "An experimental study on confluence of Two Foot Traffic Flows in Staircase" (31) by $\mathbb{A}$. Hokugo.

(2) Identifying the time for reporting and stretcher-transferring by experiments.

This is omitted here, because they are already mentioned above.

By system engineering method.

Studies are made using a network model of escape routes for evalua- 
tion on planning of buildings.

Examples include "On Measuring Escapability from a Maze"(32) by H. Yoshimura, "Network Models for Building Evacuation"(33) by L. G. Chalmet, R. L. Francis, and P. B. Saunders, and "Study on the Evaluation of Planning for Safe Escape with Consideration of Smoke Movement"(34) by $\mathrm{T}$. Terai, K. Matsushita, et al.

\section{Classification by Countermeasures}

In terms of reliability of facilities and equipment. Studies have been made on how people act when a fire detector incorrectly alarms and on the relation between equipment inspection and malfunction. The following studies clarify reliability and effectiveness of facilities using data from the inspection of fire extinguishing equipment conducted by fire officials, as well as examining to what extent reliability can be improved through proper maintenance.

M. Tsujimoto: Operational Reliability of Fire Door Interlocking with Smoke Detector $(35)$

T. Jin : Operational Situation and Evaluation of Fire Protection Equipments $(36)$

M. Kobayashi : Systems Analysis of Building Fire Safety ${ }^{(37)}$-- Part 2: Effectiveness of Fixe Extinguish Equipments

K. Nakamura : Seeking for Safe Residential Space: Technique to cope with Emergencies (38)

In terms of management system. The Fire Defense Agency prepared the following manual regarding the management system for the nighttime fire protection at inns and hotels in cooperation with the Fire Protection Equipment and safety Center. This manual shows how to evaluate whether the necessary actions would be completed within the allowable time fixed as requixed to cope with fires.

K. Kobayashi : Instruction Manual on Management System for the Nighttime Fixe Fighting at Inns and Hotels (39)

The following is the sumary of the foregoing:

(1) Recent researches are apt to be increasingly sophisticated, taking advantage of the computer simulation method for developing behavior models, incorporating various related factors and making forecasts on egress behavior in case of emergencies.

(2) Also researchers in engineering fields, researchers in psychology, statistics, sociology, etc. have accomplished more and more studies. Studies related to fire prevention (protection against outbreak of fires, anti-fire education, etc.), are now being made in a wider range than ever after a period of low activity.

\section{KEY CHAILENGES IN FUTURE RESEARCH}

Problems on Forecasts of Evacuative Behavior 
As mentioned above, recent studies using computer simulations to make forecasts on evacuation behavior during fires seem to have become more sophisticated and more active.

However, this trend may lead to researchers losing the oxiginal goals of their studies, possibly leading to providing incorrect results.

For example, in facilities such as hospitals, homes for the aged, infant homes, etc. homes to accommodate physically and mentally handicapped people, for whom conventional means of egress are inappropriate, the first and most important step is to complete divisions for fire extinguishing and smoke blocking by early detection of fires (shown in $C$, D, E of Figure 1, and in (c), (d), (e) of Table 1). Then, appropriate measures should be taken for assisted and escape.

on the other hand, in department stores, theaters, halls, etc. accommodating many and unspecified people, it is more appropriate to put emphasis on guidance and escape than to make counterplans of divisions for fire protection and fire fighting.

As an evaluation method of evacuation plans, it is risky to pay attention only to the time criteria such that "if the time consumed for evacuation to a safety area by all the people involved does not exceed the given time, it is regarded safe". Reviews must be made by making a point of "selection of escape directions", "detection of points causing stagnation or confusion of the crowd among escape routes and preventive means against occurrence of dangers such as tumbles at these points".

\section{Necessity of Research on Preventive Means before Fire}

As shown in Figure 1 and Table 1 above, the field of fire prevention has been less studied compared to means to be taken after fire outbreaks. Especially in the field of $A$ and (a) shown in the said Figure and Table, topics such as psychology must be accomplished, because human factors are deeply involved; however, efforts in this field have been insufficient so far. Therefore, the recent trend to increase studies by researchers in human sciences is highly appreciated, and closer communications among researchers in each field is a key in future development.

Since few researches have been made in this field on the whole, the following tasks are expected to be tackled in future.

(a) Research on the mechanism of fire outbreaks, especially people are involved, must be made for effective implementation of preventive means.

(b) In terms of fire prevention for the aged, infants, and the handicapped, research must be made on some effective methods combined with other means, such as the use of a pocket-sized alarm in an emergency report and flame retardant fabrics for clothes and bedding, and so on.

Promotion of Research for Decrease of Casualties due to Residential Fires

In seeking to decrease fatalities due to residential fires, which account for 70-80\% of the total fatalities by fire, the use of a fire 
detector and simple sprinkler for home use, showing a successful result in the U.S., should be widely spread. In the light of this, research and investigation must be made on enlightenment and spreading activities for citizens, especially for all family members including women and children, as well as on administrative guidelines and method of assistance.

\section{REFERENCE}

(1) Togawa, K. A Study on Evacuation Facilities through observation Crowd Flow. Report of the Building Research Institute (Japan). No. 14 $155-2$

(2) Fire Information Research Center (Japan). Report of Research and Development of simulation Model in fire situation. $185-3$

(3) Kato, T. Human Behavior in case of Fire (Time to start for Evacuation). Summeries of Technical Papers of Annual Meeting of A.T.J. p. $709-7 \overline{10}: 77-10$

(4) Building Research Institute (Japan). Development of Design system for Building Fire Safety (Design Method of Snoke Control and Evacuation). Project on Development of Design System for Building Fire Safety 1985. '186-3

(5) Murosaki, Y. et al. A Study on Hospital Evacuation Planning. Summeries of Technical Papers of Annual Meeting of A.I.J. (planning) p. 287-290'86-8

(6) Nomura, T., Hagita, A. Shiokawa, N. A Study on the Refuge Ability of Mentally Retarded Persons. Summeries of Technical Papers of Annual Meeting of A.T.J. (planning) P. $1365-1368$ '83-9

(7) Archea, J. The Evacuation of Non-Ambulatory Patients from Hospital and Nursing Home Fires: A Framework for a Model. NBSIR 791906 (U.S.A.) 179

(8) Shida, K, et al. Moving Ability of Patients in Hospital for Evacuation. Journal of JAFSE. "Fire" Vol. 35 No. 6 (Whole No. 159) P. $27-3 \overrightarrow{2} \cdot \overrightarrow{85-1}$

(9) Jin, T. Experimental Study of Human Behaviox in Smoke filled Corridor. Paper for the second International Symposium of IAFSS. ' $88-6$

(10) Hokugo, A. An Experimental Study on Evacuational Ability in smoke. Journal of Arch. A.I.J. (planning) No. 353 P. 32-38 '85-9

(I1) Watanabe, Y. Experiment on Human Behavior in Evacuation through Maze (Part 1): Memory of Walk Route. Journal of Arch. A.I.J. (planning) No. $322 \mathrm{p} \cdot 157-164$ '82-10

(12) Watanabe, $Y$. (the same as above 11.) (Paxt 2): Learning of Walk Route. Journal of Arch. A.I.J. (planning) No. 340 p. 169-176 ' $84-11$

(13) Watanabe, Y. (the same as above 11.) (Part 3): Search Action for Exit. Journal of Arch. A.I.J. (planning) No. 347 p. 102-109 ' $85-9$ 
(14) Yung, M. Study on the Influence of $C O$ upon the Evacuation Abili ties. Summexies of Technical Papers of Annual Meeting of JAFSE. p. $29-30 \quad \cdot 86-5$

(15) Yung, M. Study on the Space Recognition of Evacuee through Maze. Summeries of Technical Papers of 17 th Symposium of Japan Society for Safety Engineering. 187-7

(16) Hayashi, C. On the Significance of Disaster Prevention Education to Primary School Pupils. Study Note of Disaster Prevention Education No. $2: 86-3$

(17) Mizuno, K. Disaster Prevention Media and Education. Text of Fire Science Seminax of JAFSE. ' $85-10$

(18) Horiuchi, S., Murosaki, Y., Hokugo, A. et al. A Case Study of Fire and Evacuation in a Multi-Purpose office Building, Osaka, Japan. Proceedings of the First International Symposium of IAFSS. p. 523-532 "85-10

(19) Bryan, J.L. An Examination and Analysis of the Dynamics of the Human Behavior in the MGM Grand Hotel Fire. Publication of N.F.P.A. NO. LS-5 ' $83-4$

(20) Tokyo Fire Department. Report of the Analysis and Evaluation of Unusual Building Fires. ' $183-3$

(21) Hokugo, A. A Study on Behavior Patterns in Fire in Relation to the Type of Building. Journal of Arch. A.I.J. (planning) No. 347 p. $28-33 \cdot 85-1$

(22) Stahl, F. BFIRES II: A Behavior basea Computer Simulation of Emergency, Egress duxing Fires. Fire Technology (N.F.P.A.) p. $49 \cdot 82-2$

(23) Sato, H. et a1. Computer Simulation for Total Fire-Safety Design of the New Japanese "SUMO" Wrestling Headquarters and Stadium. Proceedings of the First International Symposium of IAFSS. p. 541-550 "85-10

(24) Alvoid, D.M. Status Report of Escape and Rescue Model. NBS-GCR $83-432$ (U.S.A.) $183-6$

(25) Murosaki, y. et al. Study on the Evacuation Simulation for supporting Behaviors. Summeries of Technical papers of Annual Meeting of A.I.J. (planning) p. 615-618 '87-10

(26) Shida, K. et al. Evaluation Methods of life Risk in case of Building Fires. Journal of Arch. A.I.J. (planning) No. 368 p. $69-78 \cdot 86-10$

(27) Sime, J.D. The Eire "Game": Future Direction for Research and Development. Fire Protection p. 10-17'85-2

(28) Kobayashi, K. Attack to the "Simulation Game for Hotel Fires" Journal of Fire Protection Equipment and Safety Center of Japan, "FESC" No. 6, No. 7, No. 8 $78-6,7,8$ 
(29) Iwaki, K. An Attempt of Evacuation Practice as a Game. Preparing Paper for Master's Thesis of Tsukuba Univ. '87-12

(30) Hokugo, A. et al. Experimental Study on Escape Direction: Analysis of Responses to Pairs of Slide projections. Journal of Arch. A.I.J. (planning) No. 339 p. 84-89 '84-5

(31) Hokugo, A. et al. An Experimental study on confluence of Two Foot Traffic Flows in Staircase. Journal of Arch. A.I.J. (planning) No. 358 p. $37-43$ "85-12

(32) Yoshimuxa, $\mathrm{H}$. On Measuring Escapability from a Maze: A Study on Arrangement of Fixe Escape in a Building (Part 1). Journal of Arch. A.I.J. (planning) No. 375 p. 49-56 '87-5

(33) Chalmet, L.G., Francis, R.L., Saunders, P.B. Network Model for Building Evacuation. Fire Technology (N.F.P.A.) p. 90 ' $81-3$

(34) Terai, T., Matsushita, K., Fukai, H. Study on the Evaluation of Planning for Safe Escape with Consideration of Smoke Movement. Journal of Arch. A.I.J. Kinki-branch p. 20l-204 '85-5

(35) Tsujimoto, M. Operating Reliability of Fire door Interlocking with Smoke Detector. New Guide Book of Smoke Control Technics, Building Center of Japan 187 edition p. 202187

(36) Jin, T. Operational Situation and Evaluation of Fire Protective Equipments. Research on Disasters Vol. 18 p. 156 published by Disaster Prevention Committee in Non-Life Insurance Society. $187-3$

(37) Kobayashi, M. System Analysis of Building Fire Safety: (Part 2) Effectiveness of Fire Extinguishing Equipments. Journal of Arch. A.T.J. (planning) No. 351 p. 20-26 '85-6

(38) Nakamura, K. Seeking for Safe Residential space: Technique to cope with Emergencies. News of Industrial Products Research Institute. Vol. 19, No. $\frac{19}{4 \cdot 87-7}$

(39) Kobayashi, K. Instruction Mannual on Management system for the Night time Fire Fighting at Inns and Hotels. Fire Man Journal published by "Zenkoku Kajohorei Publishing Co." p. 76 '87-10 